\title{
Situation in Special Education: Interaction between Teachers and Children Who Have Intellectual Disability and Who Display Challenging Behaviours
}

Ioanna Guikas

Université du Québec à Montréal

Diane Morin

Université du Québec à Montréal

\begin{abstract}
Interactions between staff and individuals with intellectual disability have been shown to influence the development or maintenance of challenging behaviours among the latter. Given the implications of these observations, the present study sought to describe special education teachers' responses to challenging behaviours displayed by their pupils. Eight teachers and 12 children with intellectual disability who manifested challenging behaviours were observed over the course of six months. Teachers completed questionnaires regarding their emotional reactions to, and understanding of, challenging behaviours. They also
\end{abstract}


reported their behavioural and emotional responses to challenging behaviours described in vignettes. The combination of observation and questionnaires provided a more comprehensive understanding of teachers' attitudes toward challenging behaviours. Results indicated a discrepancy between reported and observed behaviours. Teachers preferred verbal interventions or not responding to challenging behaviours. The analysis of interactions between teachers and their pupils highlighted relationships between emotions, attributions, and several behaviours.

Keywords: attitude, attribution, challenging behaviour, emotions, observation, teachers

\section{Résumé}

Les études ont démontré que les interactions entre les intervenants et les personnes ayant une déficience intellectuelle peuvent avoir un effet sur le développement ou le maintien des troubles du comportement chez ces dernières. Considérant la portée de ce constat, la présente étude propose une analyse descriptive des réactions des enseignants travaillant dans des classes spéciales face aux comportements problématiques de leurs élèves. Huit enseignants et douze enfants ayant une déficience intellectuelle et présentant des troubles du comportement ont été observés pendant une période de six mois. Les enseignants ont rempli des questionnaires permettant de recueillir de l'information concernant leurs émotions face aux troubles du comportement et leur compréhension de ces derniers. Ils ont également fait part de leurs réactions comportementales et émotionnelles en réponse à des comportements problématiques décrits dans des mises en situation. L'observation associée aux questionnaires a permis une compréhension plus globale des attitudes des enseignants envers les troubles du comportement. Les résultats démontrent que les comportements observés diffèrent des comportements rapportés. Il apparaît que les enseignants favorisent les interventions verbales ou n'interviennent pas face aux troubles du comportement. L'analyse des interactions entre les enseignants et leurs élèves met en évidence le lien existant entre les émotions, les attributions et plusieurs comportements.

Mots-clés : attitude, attribution, comportements problématiques, émotions, observation, enseignants 


\section{Introduction}

Between 10 and $60 \%$ of people with intellectual disability (ID) of all ages manifest challenging behaviours (Crocker et al., 2006; Emerson et al., 2001; Holden \& Gitlesen, 2006; L'Abbé \& Morin, 2001; Willaye \& Magerotte, 2008). According to Tassé and colleagues (2010), challenging behaviours are defined as follows: "Action or set of actions that are judged to be problematic because they deviate of the social, cultural or developmental norms and they are prejudicial to the person or to her social or physical environment" (p. 68).

Children with ID are more likely to present challenging behaviours than their typically developing peers (Einfeld \& Tonge, 1996; Wallander et al., 2003; De Ruiter et al., 2007). Challenging behaviours have been shown to seriously impair children's academic trajectory (French \& Conrad, 2001), to affect their development and social integration (Hudson et al., 2003), and to have a negative effect on their teachers (Kelly et al., 2007; Male \& May, 1997a, 1997b). Although challenging behaviours have a complex aetiology, several researchers agree that the quality of interactions between persons with ID and staff is a major factor in their development or maintenance (Embregts et al., 2009; Hastings \& Remington, 1994).

Staff members' attitudes may influence the nature, severity, and frequency of challenging behaviours manifested by people with ID (Hastings, 2005). While a substantial body of research has examined this issue (Cudré-Mauroux, 2010; Lambrechts et al., 2009, 2010; Wanless \& Jahoda, 2002; Zijlmans et al., 2012), our understanding of this phenomenon nevertheless remains in its early stages and would benefit from further inquiry. The present study applies a tripartite model of attitudes to interactions between teachers and pupils with ID who engage in challenging behaviours toward others and toward their environment. According to this approach, attitudes consist of emotional, cognitive, and behavioural components (Rosenberg \& Hovland, 1960; Zanna \& Rempel, 1988).

\section{Challenging Behaviours and Teachers' Emotions}

Studies have shown that staff may feel fear, anger, and frustration toward persons with ID who engage in challenging behaviours (Hastings, 1995; Mitchell \& Hastings, 1998). Staff also express depressive feelings in response to service users' challenging behaviours (Bailey et al., 2006; Lambrechts et al., 2009). Thus, challenging behaviours may have 
repercussions on staff psychological well-being (Hensel et al., 2012). Indeed, staff who are exposed to these behaviours experience workplace stress (Hastings, 2002; Jenkins et al., 1997; Kozak et al., 2013) and report higher levels of anxiety than their colleagues who work with persons with ID who do not manifest challenging behaviours (Jenkins et al., 1997). The day-to-day build-up of negative emotions in response to challenging behaviours may lead to burnout (Bailey et al., 2006; Chung \& Harding, 2009; Hastings, 2002; Hensel et al., 2012; Mills \& Rose, 2011; Mitchell \& Hastings, 2001). In fact, a study by Kelly and his colleagues (2007) showed that $93 \%$ of teachers who worked with pupils with ID and challenging behaviours experienced emotional exhaustion.

\section{Challenging Behaviours and Teachers' Attributions}

Individuals will form attributions (i.e., beliefs and opinions) in an attempt to explain difficult situations that they face (Cudré-Mauroux, 2010). These attributions may lead to different attitudes and interventions. Research suggests that staff's sociodemographic characteristics such as experience and training may influence the attributions they have regarding challenging behaviours (Grey et al., 2002; Hastings et al., 1995). Staff express a range of causal attributions of users' challenging behaviours, depending on the type of behaviour (Dilworth et al., 2011). Emerson and Bromley (1995) and Grey and colleagues (2002) obtained discrepant findings regarding staff members' attributions of challenging behaviours. In Emerson and Bromley (1995), 41\% of staff thought that challenging behaviours stemmed from service users' internal state or mood, $26 \%$ believed they were the result of self-stimulation, $23 \%$ attributed these to a desire to communicate, and the remaining $17 \%$ thought that service users were seeking attention. In contrast, Grey and colleagues (2002) concluded that the majority of staff believed that challenging behaviours were learned through positive reinforcement $(90 \%)$ or were a result of the person with ID's emotional state (50\%). Though these results are enlightening, it is difficult to draw conclusions regarding the accuracy and relevance of staff attributions when the causes of challenging behaviour vary across situations and individuals.

\section{Challenging Behaviours and Teachers' Behaviour}

The actions or inactions of staff may influence people with ID's challenging behaviours. There is no empirical consensus regarding staff behaviour toward service users. Hastings 
and Remington (1994) showed that staff spent little time interacting with service users and that these interactions were of poor quality. Another study demonstrated that poor social interactions are positively correlated with the manifestation of self-injurious behaviours among children with ID (Hall et al., 2001). Staff may respond to challenging behaviours with hostility (Jahoda \& Wanless, 2005; Zijlmans et al., 2012), intermittently, or occasionally in a way that might reinforce these behaviours (Hastings \& Remington, 1994). However, other studies report that staff may use alternative, positive interventions (soothing the person, providing additional assistance during an activity, etc.) when faced with challenging behaviours (Lambrechts et al., 2009).

\section{Relationships between the Three Dimensions of Attitudes}

The relationships between the cognitive, emotional, and behavioural dimensions of attitudes toward challenging behaviours remain unclear (Cudré-Mauroux, 2010). Researchers have highlighted a need for further investigations into the three dimensions of these attitudes, using various measures (Zijlmans et al., 2012) and naturalistic observation (Hastings \& Remington, 1994; Hastings \& Brown, 2000; Lambrechts et al., 2010). To date, most studies have used questionnaires, vignettes, or interviews to measure attitudes (Hastings, 1995; Lambrechts et al., 2009; Wanless \& Jahoda, 2002; Zijlmans et al., 2012), potentially overlooking some aspects of the phenomenon (Lambrechts et al., 2010; Van Oorsouw et al., 2011). Wanless and Jahoda (2002) have shown that vignettes elicit weaker emotional responses than do real-world situations. These also neglect the behavioural component of the interaction and may be biased by social desirability.

Antonak and Livneh (1988) proposed that the behavioural dimension could be measured by observing individuals within the contexts in which the attitude of interest manifests. However, this method is rarely used to assess attitudes toward persons with ID who engage in challenging behaviours (Mossman et al., 2002), despite its usefulness in situations that involve interactions (Gardner, 2000; Iacobucci \& Wasserman, 1988). Furthermore, few studies have analyzed the relationship between teachers and pupils with ID who display challenging behaviours (Male \& May, 1997a, 1997b; Rae \& Murray, 2011) or observed staff responses to children with ID's challenging behaviours (Hastings, 1997a, 2005; Mossman et al., 2002). Finally, most investigations of this phenomenon 
have examined the interactions between staff and service users with severe or profound ID (Lambrechts et al., 2010).

\section{Objectives}

The present study sought to (1) describe pupils' challenging behaviours in special education classrooms, (2) describe the three components of teachers' attitudes (cognitive, emotional, and behavioural) toward challenging behaviours according to the tripartite model, and (3) present the relationships between the three components of teachers' attitudes.

\section{Methods}

\section{Participants}

Five schools were contacted to participate in the survey but only one agreed to take part in the study. There was no relation between the researcher and the recruited school. Participants were special education teachers and their pupils. Eight teachers who worked in the school in question, the majority of whom were women $(n=6)$, agreed to participate. Their age ranged between 31.7 and 47.5 years $(M=40.9, S D=8.73)$. They had worked in special education settings for an average of 12.6 years. Six teachers held an undergraduate degree, one had a master's degree, and another had a collegial degree (a level of education occurring between high school and undergraduate education). Seven teachers $(88 \%)$ had received specific training in ID and five $(63 \%)$ had been trained in challenging behaviours. Teachers were required to have worked for a minimum of three months with the same group of pupils to be included in the present study. This criterion ensured that they had sufficient knowledge of their pupils (personality, strengths, and difficulties) and that the latter were familiar with classroom rules. Teachers had an average of 8.6 pupils per classrooms, with one to four of these children manifesting challenging behaviours.

Twelve pupils aged between 4.9 and 7.7 years $(M=6.5, S D=0.81)$ who had mild ID and presented challenging behaviours participated in the study. Fourteen children were initially selected to participate but two had to be excluded from the statistical 
analyses because they were frequently absent and did not display a sufficient number of challenging behaviours. Of the 12 remaining participants, 10 were boys and two were girls. According to teachers' reports in the demographic information forms, four pupils presented a genetic syndrome (33\%) and three had a mental health disorder (25\%). All but one of the children were able to communicate verbally. An individualized intervention plan designed to promote the child's learning and functioning and to monitor his or her progress had been implemented for each pupil. Teachers ensured that the pupils met inclusion criteria for the research: (a) presence of a diagnosis of intellectual disability, (b) presence of aggressive behaviours toward others or toward the environment, and (c) age between four and eight years old. The provided information was validated with the school psychologist. Children with an autism spectrum disorder were excluded from the study as the services they receive differ greatly from those of children with ID, both in terms of the type of interventions they receive and of their frequency and duration (Ministère de l'Éducation du Loisir et du Sport, 2006).

\section{Procedure}

This study was approved by the research ethics board of the University of Quebec in Montreal. The study was conducted in two steps. The teachers and psychologist at the participating school were given two information sessions providing an overview of the study and answers to their questions. Special education teachers and their students with ID were recruited to take part in the naturalistic observation portion of the study. Teachers were asked, in writing, to provide consent to participate in the study. Additionally, teachers contacted each pupil's parents in order to request in writing their consent for their child to be filmed in class. A total of 53 families were asked for consent to participate in the study. All parents of each of the pupils were asked for consent, whether or not their child presented the inclusion criteria, as all pupils were filmed in class. Only the children that met the inclusion criteria were observed. Of the 53 families, only one family refused that their child be filmed. Even if this child did not meet the inclusion criteria, the research team did not film the class when this child was present. The research team was informed when he was absent or when he had activities that were taking place outside of the classroom (e.g., sessions of speech therapy, art therapy) and filming was conducted during these time periods. Teachers completed all the documents (sociodemographic 
forms for their pupils and themselves, questionnaires, and vignettes) necessary for the study.

Teachers and their pupils were filmed over the course of six months, for a total of 120 hours. As the observation was carried out in naturalistic settings, the researcher had to adapt the observation periods to the schedule of the teachers. For example, observations were not carried out when teachers were doing special activities (e.g., dress up day, sportive day) or when additional individuals, who were not participants from the study, were present in class (e.g., presence of an intern). These circumstances resulted in changes in the observation schedule for the researcher but did not have an impact on the teachers or the pupils. As a result, there was variability in observation durations and moments of observation accross teachers. Generally, the researcher or her research assistant was present twice a week, in the morning at school. Periods of observation lasted between one hour and three hours, depending on class activities.

\section{Instruments}

Sociodemographic forms. Teachers completed two sociodemographic forms. The first one collected information on the teachers' age, training, years of experience, etc. The second form collected information on pupils' age, gender, level of ID, presence of challenging behaviours, diagnoses, intervention plan, and so on.

Emotional reactions. The Emotional Reactions to Challenging Behaviour Scale (ERCB; Jones \& Hastings, 2003; Mitchell \& Hastings, 1998) was used to assess the emotional component of attitudes toward challenging behaviours. The average time to complete this scale was approximately 10 minutes. The instrument consists of four subscales: depression/anger, fear/anxiety, confident/relaxed, and cheerful/excited. It includes 23 items, of which 15 reference negative emotions (e.g., angry, incompetent, frightened) and eight positive emotions (e.g., confident, happy, relaxed). Respondents rated the emotions they experienced when children displayed challenging behaviours on a four-point scale ranging from 0 (no, never) to 3 (yes, very frequently). Subscale scores were calculated by averaging ratings on all of the items belonging to the same subscale. The internal consistency of the fear/anxiety and confident/relaxed subscales ranged between Cronbach's $\alpha=0.75$ and 0.86 . In contrast, the cheerful/excited and the depression/anger subscales 
achieved $\alpha=0.58$ and 0.60 , respectively. The authors report that the questionnaire attained good overall internal consistency, along with good test-retest reliability and construct reliability, and to be relatively unaffected by social desirability (Mitchell \& Hastings, 2001). The authors of the present study have translated this instrument to French using a committee approach (Tassé \& Craig, 1999). This translation achieved excellent internal consistency on the cheerful/excited subscale $(\alpha=0.92)$, good internal consistency on the depression/anger subscale $(\alpha=0.84)$, and acceptable internal consistency on both the fear/anxiety subscale $(\alpha=0.73)$ and the confident/relaxed subscale $(\alpha=0.65)$ (Nunnaly, 1967).

Causal attributions. Staff attributions of challenging behaviour were measured with the Challenging Behaviour Attributions Scale (CHABA; Hastings, 1997b). The average time to complete this scale was approximately 10 minutes. Teachers were given a description of challenging behaviours and were asked to indicate why their pupil might engage in such challenging behaviours. Statements include five causal interpretations: behavioural learning (through positive reinforcement, e.g., they want something; or negative reinforcement, e.g., they want to avoid uninteresting tasks), medical/biological factors (e.g., they are physically ill), emotional factors (e.g., they are angry), aspects of the physical environment (e.g., their house/classroom is too crowded with people), and stimulation (e.g., they are bored). Teachers were asked the likelihood of 33 possible causes for aggressive behaviours on a five-point scale ranging between -2 (very unlikely) to 2 (very likely). Subscale scores were calculated by averaging ratings on all the items belonging to the same causal interpretations. A subscale score below zero indicates that teachers considered this cause unlikely to explain the behaviour. A subscale score above zero indicates that teachers considered the cause likely to explain the behaviour. The instrument achieved good internal consistency ranging between $\alpha=0.65$ and 0.87 across dimensions (Hastings, 1997b). This instrument was also translated to French by the authors of the present study using a committee method (Tassé \& Craig, 1999). The internal consistency of the French version was acceptable for the stimulation $(\alpha=0.74)$, physical environment ( $\alpha=0.74)$, and learned negative $(\alpha=0.70)$ subscales. It was minimal for the emotional ( $\alpha=0.57)$, learned positive $(\alpha=0.55)$, and for the biomedical $(\alpha=0.41)$ scale, which calls into question the validity of this scale (Nunnally, 1967). 
Responses to challenging behaviours: Vignettes. Responses to challenging behaviours were measured with vignettes created for the study. The average time to complete this instrument was approximately 10 to 20 minutes. Vignettes described three situations: (a) challenging behaviour toward objects (a child destroying classroom materials), (b) challenging behaviours toward another child (a child assaulting one of his peers), and (c) challenging behaviour toward the teacher (a child assaulting his teacher). Respondents were asked to describe what intervention they would implement to prevent each situation, as well as the intervention they would implement after a child had manifested this type of behaviour. They were also asked to describe their emotional reactions to such situations. Two coders analyzed responses to these vignettes and classified the responses regarding the intervention according to the schedule used for behavioural observation (Guikas et al., 2016) and the responses regarding the emotion according to the categories of the ERCB (depression/anger, fear/anxiety, confident/relaxed, and cheerful/excited). The coders attained an inter-rater reliability of $r=0.87$.

Behavioural observation. A behavioural observation schedule presented in Guikas et al. (2016) was used to observe interactions between teachers and their students. The instrument consisted of 15 behaviours that were regrouped into three categories of behaviours to observe teachers': (a) physical behaviours (e.g., removing the stimulus, physical intervention), (b) verbal behaviours (e.g., explaining the consequences or risks of the behaviour, reducing demands), and (c) other behaviours (e.g., modelling, no intervention). To observe pupils, the observation schedule contained nine behaviours regrouped in three categories: (a) physical behaviours (e.g., destruction of property, aggression towards a peer), (b) verbal behaviours (e.g., screaming, insults/teasing), and (c) other behaviours (e.g., not following instructions/opposition to a request).

The systematic data collection stage consisted of filming eight teachers and 12 children with ID displaying challenging behaviours over the course of six months. Of the 120 hours filmed, 60 hours of the data were coded using the software program The Observer XT (Noldus Information Technology, 2012). The duration of each observation and the number of hours filmed for each participant varied as the observation was carried in naturalistic settings. Ratios were calculated to normalize the data. The first sessions of observation for each teacher and their pupils were not coded to prevent bias (three hours for each teacher). Videos that had technical problems or in which the typical functioning 
of the class was disturbed (e.g., a large number of students were missing) were not coded. Each video was digitized to an AVI format and was imported into The Observer XT (Noldus Information Technology, 2012). A key code was paired to each behaviour from the observation schedule (e.g., key "D" for the behaviour "drawing attention/diversion"). Coding was conducted using a continuous sampling method and recorded each occurrence of pupils' challenging behaviours. Subsenquently, teachers' reactions were registrered. A time was associated to each keypress. This allowed the coders to record precisely every behaviour for each participant. When different behaviours occurred at the same time or in rapid succession (e.g., two selected students displaying challenging behaviours at the same time) each behaviour was coded independently. The utilisation of the software also permitted multiple viewing of the videos and corrections or changes in the recording. Coding one hour of video took on average five hours. Videos were coded by three doctoral students and one undergraduate student in psychology. All three coders had received complete and thorough training on the use of the observation schedule. Definitions, examples, and counter-examples for each behaviour of the observation schedule (Guikas et al., 2016) were presented to the coders and the researcher made sure that there was an agreement regarding the behaviours that needed to be coded. In order to ensure coding reliability, a random selection of $10 \%$ of total videos were coded by two observers. An inter-rater reliability coefficient of $\kappa=0.79$ (Cohen, 1960) and test-retest reliability (over a span of six months) of $\kappa=0.86$ were achieved, confirming the observation schedule's reliability.

\section{Analyses}

The software program The Observer XT (Noldus Information Technology, 2012) was used to compute the frequencies of teachers' and pupils' behaviours (Table 1). The remainder of the analyses were conducted using Microsoft Excel and the Statistical Package for the Social Sciences software. Responses to vignettes were classified according to the schedule used for behavioural observation (Table 2) and to the ERCB (Figure 1). Spearman correlational analyses were carried out to understand teachers' attitudes toward challenging behaviours manifested by their pupils. A first set of Spearman correlations coefficient was computed to assess the relationship between teachers' behaviours as observed in classroom settings and the variables included in questionnaires and vignettes 
(Table 3). A second set of Spearman correlations coefficient investigated the relationship between teachers' emotional responses to challenging behaviours and their beliefs (e.g., causal attributions) about these (Table 4).

\section{Results}

\section{Description of Classroom Interactions}

The behaviours displayed by teachers and their pupils during the observation periods are presented in Table 1. Teachers intervened on average 44.6 times per hour toward pupils' deviant and challenging behaviours. Teachers' most frequent responses to children's deviant and challenging behaviours were "addressing the pupil / repeating instructions" $(M=$ 17.3 per hour per teacher, $S D=13.6$ ) and "no intervention" (intentional or otherwise; $M$ $=12.4$ per hour per teacher, $S D=8.3$ ). Positive interventions, whether physical or verbal, were also frequently used $(M=11.5$ per hour per teacher, $S D=6.2)$. Behaviours such as "reducing demands" $(M=0.2$ per hour per teacher, $S D=0.2)$ and "protection / self-defense" ( $M=0.1$ per hour per teacher, $S D=0.3)$ were seldom observed.

Children were most often observed "not following instructions" $(M=6.9$ per hour per child, $S D=3.3$ ) and engaging in verbal deviant behaviours such as "screaming" ( $M$ $=4.2$ per hour per child, $S D=4)$ and "making noise" $(M=3.9$ per hour per child, $S D=$ 1.9). They displayed more aggression toward their peers $(M=2.1$ per hour per child, $S D$ $=1.8)$ than towards teachers $(M=0.3$ per hour per child, $S D=0.8)$.

\section{Table 1}

Teachers' and Pupils'Behaviour

\begin{tabular}{lcc}
\hline & $M$ & Percentage \\
\hline Teachers' behaviour & & \\
Addressing the child / Repeating instructions & 17.3 & $30.3 \%$ \\
No intervention & 12.4 & $21.7 \%$ \\
Positive intervention & 11.5 & $20.3 \%$ \\
Physical intervention & 3.6 & $6.3 \%$ \\
Explaining the consequences or risks of behaviour & 3.0 & $5.2 \%$
\end{tabular}




\begin{tabular}{lcc}
\hline & $M$ & Percentage \\
\hline Requesting an apology / Conflict resolution & 2.1 & $3.6 \%$ \\
Soothing the child & 1.8 & $3.2 \%$ \\
Drawing attention / Diversion & 1.6 & $2.9 \%$ \\
Expressing feelings & 1.2 & $2.1 \%$ \\
Modelling & 0.8 & $1.4 \%$ \\
Removing the child from the situation & 0.7 & $1.3 \%$ \\
Removing the stimulus & 0.7 & $1.2 \%$ \\
Reducing demands & 0.2 & $0.3 \%$ \\
Protection / Self-defense & 0.1 & $0.3 \%$ \\
Pupils'behaviour & & \\
Not following instructions / Opposition to a request & 6.9 & $30.4 \%$ \\
Screaming & 4.2 & $18.5 \%$ \\
Making noise & 3.9 & $17.0 \%$ \\
Lack of respect for others or their space & 2.9 & $12.6 \%$ \\
Aggression toward a peer & 2.1 & $9.1 \%$ \\
Destruction of property & 1.7 & $7.6 \%$ \\
Insults / Teasing & 0.4 & $1.8 \%$ \\
Aggression toward the teacher & 0.3 & $1.2 \%$ \\
Contorsion & 0.1 & $0.2 \%$ \\
\hline Note. Percen
\end{tabular}

Note. Percentages do not sum to $100 \%$ because of rounding.

$M=$ mean number of behaviours per hour, per teacher or per pupil.

\section{Interventions Reported by Teachers}

When presented with the hypothetical situations described in the vignettes, teachers said that they would remove the child from the situation $(M=3.6,21 \%$ of the time, $S D=1.9)$ and would use diversion $(M=3.0,18 \%$ of the time, $S D=4.4)$ when they must prevent or react to one of their pupils engaging in aggressive behaviours toward their environment or toward others. They also reported managing the environment $(M=1.9,11 \%$ of the time, $S D=1.8)$ and explaining to children the consequences of their behaviour $(M=1.8$, $10 \%$ of the time, $S D=1.9$ ). 


\section{Table 2}

Interventions Reported by Teachers with the Vignettes

\begin{tabular}{lcc}
\hline \multicolumn{1}{c}{ Reported intervention } & $M$ & Percentage \\
\hline Removing the child from the situation & 3.6 & $21.2 \%$ \\
Drawing attention / Diversion & 3.0 & $17.5 \%$ \\
Managing the environment & 1.9 & $10.9 \%$ \\
Explaining the consequences or risks of & 1.8 & $10.2 \%$ \\
behaviour & & \\
Addressing the child / Repeating instructions & 1.6 & $9.5 \%$ \\
Positive intervention & 1.6 & $9.5 \%$ \\
Requesting an apology / Conflict resolution & 1.5 & $8.8 \%$ \\
Modelling & 0.9 & $5.1 \%$ \\
Physical intervention & 0.6 & $3.6 \%$ \\
Removing the stimulus & 0.4 & $2.2 \%$ \\
No intervention & 0.3 & $1.5 \%$ \\
\hline
\end{tabular}

Note. Percentages do not sum to $100 \%$ because of rounding.

$M=$ mean number of responses collected with the vignettes.

\section{Teachers' Emotions}

Teachers'emotional reactions to challenging behaviours are displayed in Figure 1.

Responses collected with the ERCB and the vignettes indicated that teachers' self-reported emotional responses varied depending on the measure used. With the ERCB, the majority of teachers said they felt relaxed/confident (52\%) and cheerful/excited (23\%). They also reported experiencing depression/anger (14\%) and fear/anxiety (11\%). By contrast, teachers described feeling depression/anger (42\%), no emotions (33\%), or confident/relaxed (25\%) in response to the vignettes. They accounted for their absence of emotions by stating that "this is a common occurrence" or "these things happen in our classroom." According to the vignettes, teachers said that they did not experience cheerful/excited or fear/anxiety emotions in response to challenging behaviours. 


\section{Figure 1}

Responses to the Emotional Reactions to Challenging Behaviour Scale and Vignettes

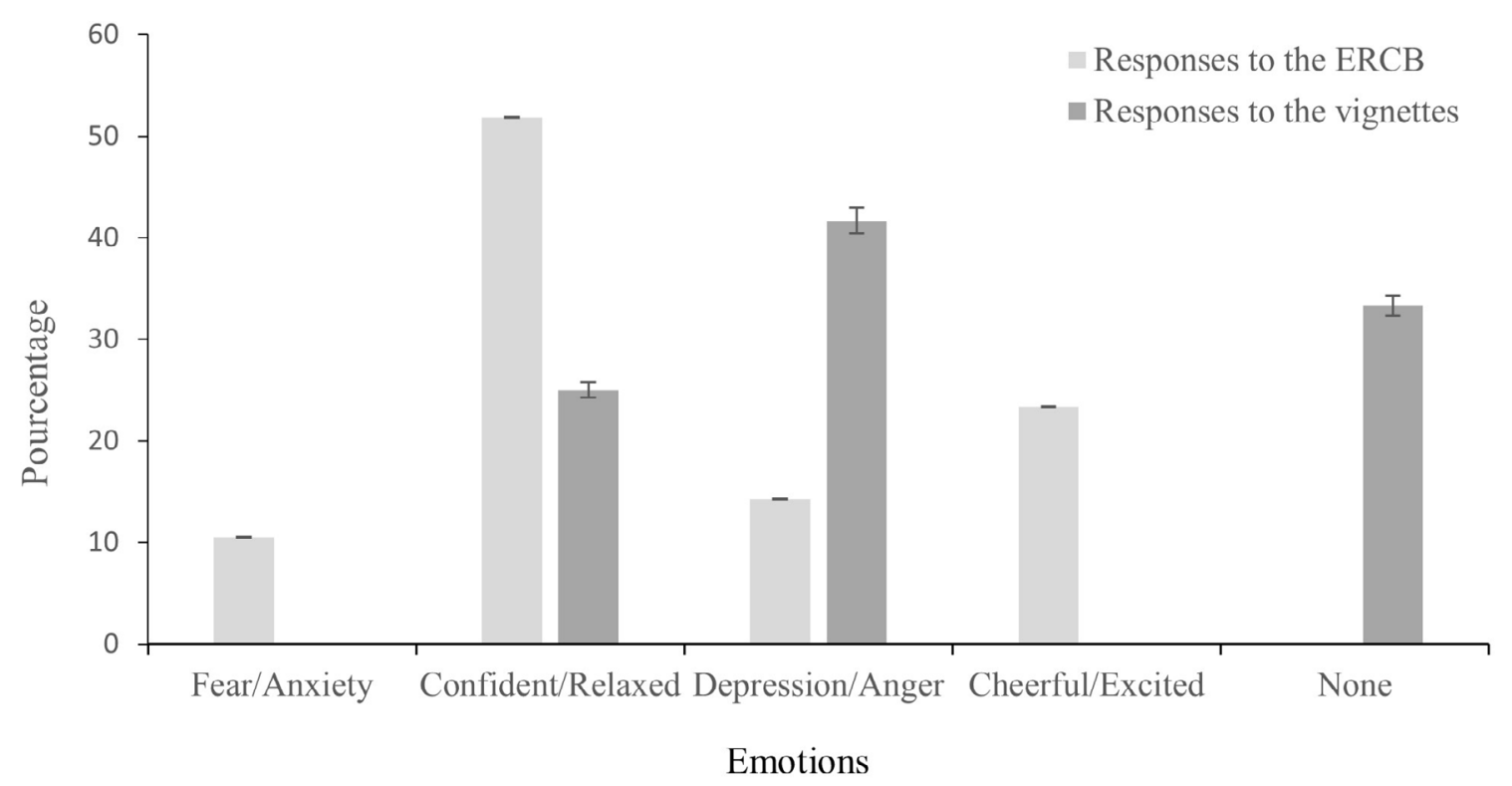

\section{Teachers' Attributions}

Teachers' causal attributions of challenging behaviours, as measured by the CHABA, are displayed in Figure 2. A subscale score below zero indicates that teachers considered this cause unlikely to explain the behaviour. A subscale score above zero indicates that teachers considered the cause likely to explain the behaviour. Teachers primarily stated that they believed challenging behaviours stemmed from children's emotions and behavioural learning through positive reinforcement. They also thought it equally likely that challenging behaviours could be the result of biomedical causes or behavioural learning through negative reinforcement. 


\section{Figure 2}

Responses to the Challenging Behaviour Attributions Scale

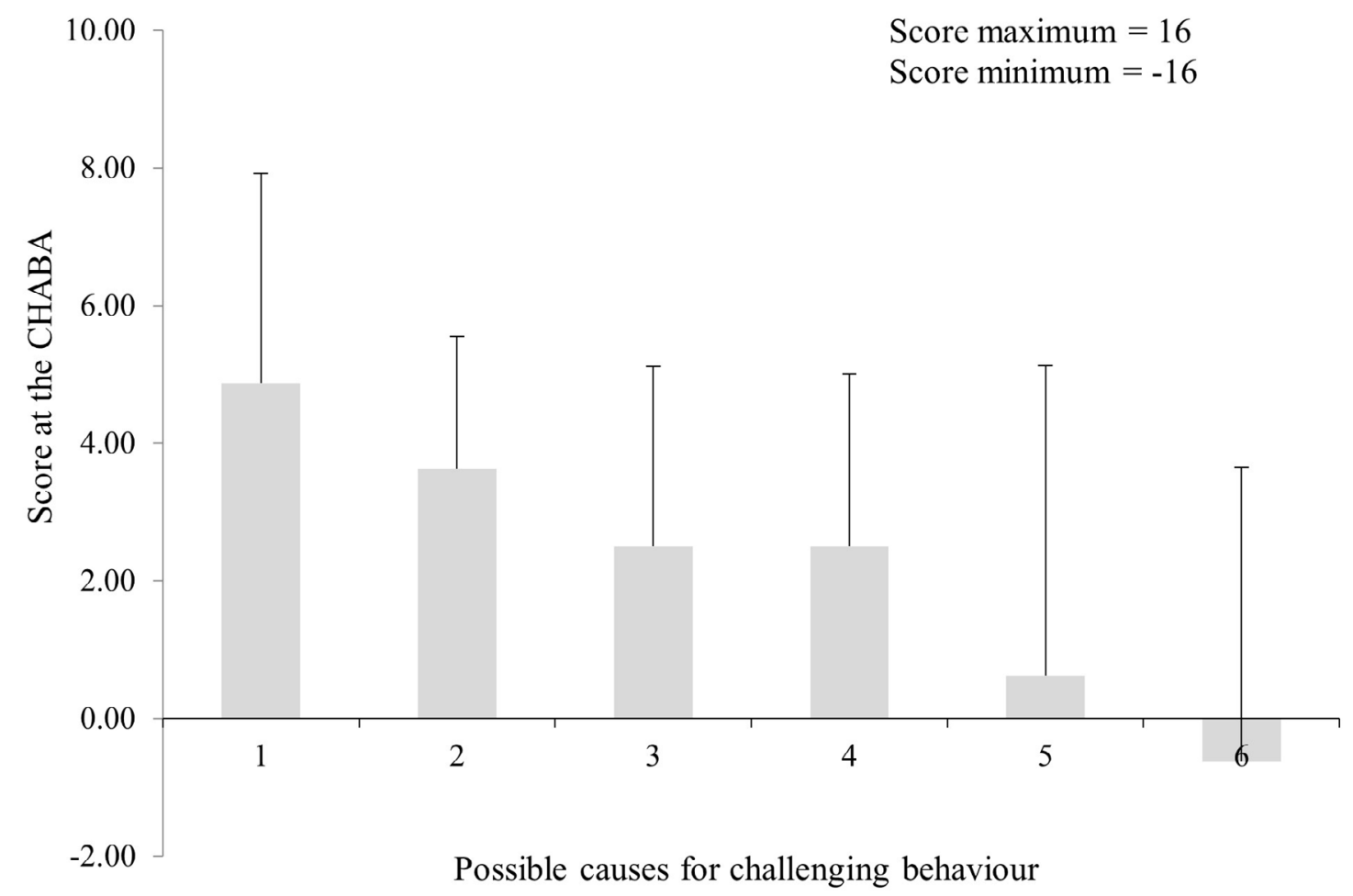

Relationship between emotions and observed behaviours. Teachers were more likely to experience negative emotions such as depression/anger $(r=0.938, p=0.001)$ when they intervened by "removing the stimulus" or "diversion" $(r=0.745, p=0.034)$. However, teachers who reported feeling cheerful/excited were more likely to express their emotions $(r=0.753, p=0.031)$.

Relationship between causal attributions and observed behaviours. Teachers who attributed challenging behaviours to biomedical causes $(r=0.872, p=0.005)$ were more likely to use positive intervention. Those who thought that challenging behaviours were due to learning through negative reinforcement were more likely to soothe the child $(r=0.849, p=0.008)$. 
Other relationships. Table 3 lists large correlations $(r>0.600)$ that did not attain statistical significance but that are interesting from a clinical perspective (Cohen, 1988). Teachers were more likely to experience negative emotions such as fear/anxiety when they removed the stimuli from the child $(r=0.693, p=0.057)$ or when they were removing the child from the situation $(r=0.705, p=0.051)$. Also, the more teachers experienced fear/anxiety $(r=0.676, p=0.066)$ or believed that challenging behaviours were due to learning through negative reinforcement $(r=0.707, p=0.050)$ the less likely they were to intervene.

\section{Table 3}

Correlational Analyses on Information Collected with Questionnaires and Observed Behaviours

\begin{tabular}{|c|c|c|c|c|c|c|c|c|c|c|c|c|c|c|}
\hline & \multicolumn{14}{|c|}{ Observed behaviours } \\
\hline & 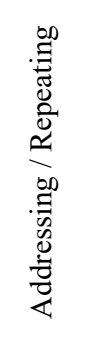 & 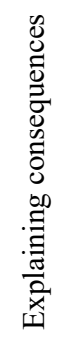 & 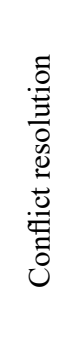 & 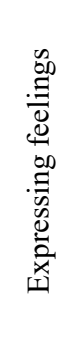 & 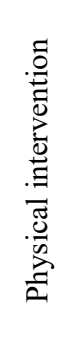 & 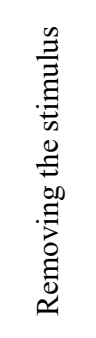 & 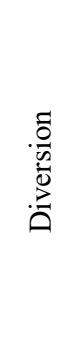 & $\begin{array}{l}\stackrel{\infty}{\Xi} \\
\stackrel{\Xi}{0} \\
\dot{0} \\
\sum\end{array}$ & 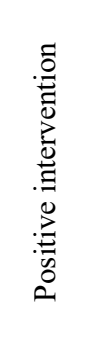 & 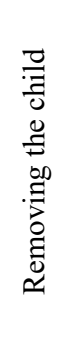 & 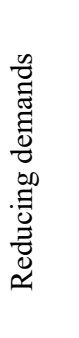 & 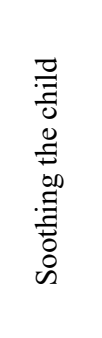 & 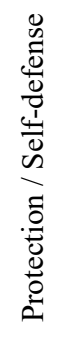 & 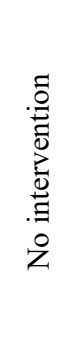 \\
\hline $\begin{array}{l}\text { ERCB: } \\
\text { fear/anxiety }\end{array}$ & .451 & .526 & .426 & .264 & .501 & .693 & .655 & .350 & .125 & .705 & -.600 & .504 & .049 & .676 \\
\hline $\begin{array}{l}\text { ERCB: } \\
\text { depression/ } \\
\text { anger }\end{array}$ & .277 & .518 & .482 & .248 & .602 & $.938 * *$ & $.745^{*}$ & .506 & .060 & .364 & -.148 & .624 & .252 & .518 \\
\hline $\begin{array}{l}\text { ERCB: } \\
\text { confident/ } \\
\text { relaxed }\end{array}$ & .072 & .217 & -.301 & .436 & -.012 & -.407 & -.121 & -.337 & .530 & .139 & -.019 & -.267 & .426 & -.325 \\
\hline $\begin{array}{l}\text { ERCB: } \\
\text { cheerful/ } \\
\text { excited }\end{array}$ & .295 & .552 & -.110 & $.753^{*}$ & .393 & .038 & .043 & -.110 & .319 & .167 & .235 & -.031 & 619 & -.258 \\
\hline $\begin{array}{l}\text { CHABA: } \\
\text { Learned } \\
\text { negative }\end{array}$ & .443 & .144 & .695 & -.127 & .443 & .552 & .476 & .611 & .228 & .084 & -.019 & $.849 * *$ & .078 & .707 \\
\hline $\begin{array}{l}\text { CHABA: } \\
\text { Learned } \\
\text { positive }\end{array}$ & .494 & .663 & .337 & .418 & .386 & .519 & .539 & .313 & .374 & .618 & -.443 & .394 & .221 & .518 \\
\hline $\begin{array}{l}\text { CHABA: } \\
\text { Biomedical }\end{array}$ & -.049 & .049 & -.061 & .006 & -.037 & -.101 & .173 & -.110 & $.872 * *$ & - & -.124 & .161 & .378 & -.037 \\
\hline
\end{tabular}




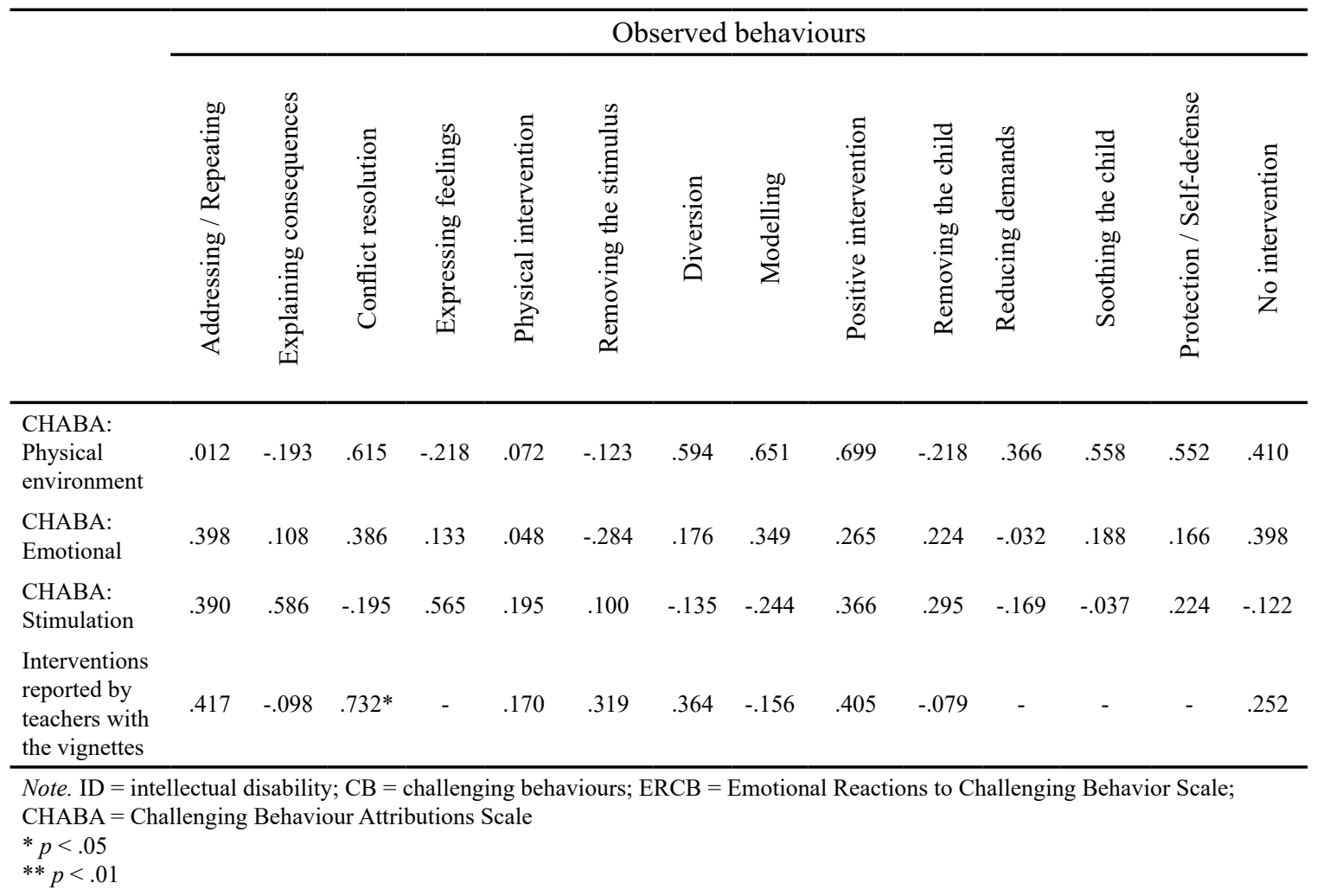

Relationship between vignettes and observed behaviours. None of the correlations between what teachers said they would do in response to challenging behaviours (vignettes) and their actual behaviours (observation) reached significance, except for "conflict resolution" $(r=0.732, p=0.039)$. Several responses, "expressing feelings," "reducing demands," "soothing the child," and "protection/self-defense" had low frequencies for the vignettes and could thus not be correlated with observed behaviours.

Relationship between emotional responses and causal attributions. Two significant positive relationships between the emotional and cognitive components of teachers' attitudes were observed. When teachers thought that challenging behaviours were the result of learning by positive reinforcement, they were more likely to experience emotions such as fear/anxiety $(r=0.849, p=0.008)$. Conversely, they experienced positive emotions such as feeling cheerful/excited if they thought that challenging behaviours stemmed from stimulation $(r=0.742, p=0.035)$. Although these correlations did not attain significance, it is interesting to notice from a clinical perspective (Cohen, 1988) that teachers who experienced positive emotions such as confident/relaxed were more likely 
to believe that challenging behaviours resulted from biomedical causes $(r=0.702, p=$ $0.052)$ or external stimulation $(r=0.704, p=0.051)$.

\section{Table 4}

Correlations between Responses to the Emotional Reactions to Challenging Behaviour Scale and Vignettes and Responses to the Challenging Behaviour Attributions Scale

\begin{tabular}{|c|c|c|c|c|c|c|}
\hline & \multicolumn{6}{|c|}{ Attributions of challenging behaviours } \\
\hline & 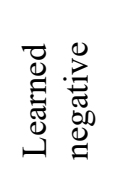 & 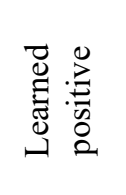 & 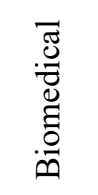 & 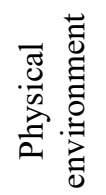 & 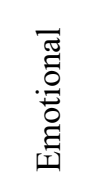 & 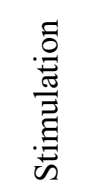 \\
\hline ERCB: fear/anxiety emotions & .365 & $.849 * *$ & .258 & .177 & .152 & .077 \\
\hline ERCB: confident/relaxed emotions & -.370 & .262 & .702 & .159 & .366 & .704 \\
\hline ERCB: depression/anger emotions & .448 & .488 & -.031 & .006 & -.354 & -.099 \\
\hline ERCB: cheerful/excited emotions & -.191 & .118 & .380 & -.118 & -.019 & $.742 *$ \\
\hline Vignettes: No emotion & - & -.139 & -.478 & -.304 & .228 & .256 \\
\hline Vignettes: depression/anger emotions & .050 & -.380 & -.361 & -.431 & -.684 & -.410 \\
\hline
\end{tabular}

Note. ERCB $=$ Emotional Reactions to Challenging Behavior Scale; $\mathrm{CHABA}=$ Challenging Behaviour Attributions Scale.

$* p<.05$

$* * p<.01$

\section{Discussion}

Teachers who work in special education classrooms with pupils who have ID experience high levels of stress and must manage many disruptive behaviours (Kelly et al., 2007). In the present study, teachers indeed spent a considerable amount of time responding to challenging or deviant behaviours displayed by their pupils; on average, teachers responded to these types of behaviours 45 times per hour. Several types of interventions listed in the behavioural observation schedule and noted in the literature were rarely observed in classrooms such as: inadequate intervention, conflict resolution, and protection behaviours. Several hypotheses may account for these findings. First, inadequate interventions, which refers to a physical intervention that is contrary to ethics and the policy of the school (e.g., grabbing the child from behind the neck) were perhaps not 
observed because teachers knew that their behaviour was being videotaped and therefore observed. Second, teachers may seldom use conflict resolution strategies with pupils who are younger and have ID. Finally, it is possible that these behaviours were not observed because challenging behaviours displayed by children aged between four and eight years are less threatening than those displayed by adults. Our observations regarding responses to challenging behaviours are otherwise generally consistent with those noted by other researchers, such as Lambrechts and his colleagues (2010): teachers used predominantly verbal interventions and rarely tried to divert the child's attention or remove the stimulus, despite vignette responses indicating teachers' use of diversion when pupils display challenging behaviours. These insights draw attention to areas that may be associated with unwitting behaviour on the teachers' part and highlight a divergence in the responsiveness and sensitivity of observation compared to vignette.

Teachers used positive interventions before and after displays of challenging behaviour, which is also consistent with findings by Lambrechts and his colleagues (2010). Although intriguing, this finding does not in itself imply that this practice is appropriate. Our observations did not specify whether positive interventions were only used for desired behaviours. It would indeed be important for teachers to reinforce desired behaviours while also avoiding reinforcement of undesirable conduct. In contrast to the study by Lambrechts and colleagues (2010), in which no behaviour was ignored by staff, our findings indicate that teachers did not respond to $22 \%$ of the challenging or deviant behaviours occurring in their classroom. This lack of response may be due to the complexity of managing a classroom environment. Additionally, "no intervention" was used to code situations in which the teacher chose not to intervene or did so involuntarily. The observation schedule did not distinguish between these two alternatives. It is therefore possible that not responding to challenging behaviours is in fact a form of intervention. For example, if the function of the challenging behaviour is to draw attention and the teacher is conscious of this phenomenon, he or she might not intervene intentionally to extinguish the behaviour. The discrepancy between our findings and those of Lambrechts and colleagues (2010) could also stem from the fact that these authors did not observe classroom environments. The range of variables (e.g., the needs of children who were not being observed, initiating and maintaining pedagogical activities, etc.) that teachers must manage in their classroom may hinder their ability to respond to all challenging or deviant behaviours. Challenging behaviours may also be perceived as aversive, such that 
teachers seek to avoid these (Hastings, 2005). Our observations suggest that teachers who experience negative emotions in response to challenging behaviours were indeed less likely to intervene, with "no intervention" being the second most frequently observed behaviour (22\%) among teachers.

In keeping with previous studies (Bromley \& Emerson, 1995; Hastings, 1995), with regards to the emotional component of attitudes, teachers reported experiencing negative emotions in general. However, they also expressed positive emotions, such as feeling confident/relaxed, which contradicts the majority of research on this topic but supports findings by Lambrechts and colleagues (2009). This discrepancy may be related to the age of persons with ID and the nature of their challenging behaviours. Here, participants were children, and few of their challenging behaviours were directed toward the teacher. These behaviours may therefore be perceived as less threatening than similar behaviours displayed by adults. The topography of behaviours has also been shown to influence staff emotions (Hastings \& Brown, 2002). We also hypothesize that the results of the present study were influenced by social desirability biases. Indeed, teachers' responses to the vignettes differed from what was collected through questionnaires. Relative to their responses to the questionnaire, teachers reported fewer emotions with the vignettes. Responding to vignettes may evoke feelings of social desirability and make it difficult for respondents to express negative emotions.

Regarding the cognitive component of teachers' attitudes toward challenging behaviours, our results are consistent with those of Grey and colleagues (2002). Specifically, emotional states and behavioural learning through positive reinforcement were the most frequent attributions of challenging behaviours. The fact that teachers thought it unlikely that these behaviours stemmed from features of pupils' physical environment or from stimulation was nevertheless surprising. Teachers said of the children "they are left to their own devices" and "they are bored." Teachers actually reported positive emotions when they believed that challenging behaviours resulted from stimulation. Their attribution of challenging behaviours to stimulation may actually stem from their observations, which are consistent with our observation, that challenging behaviours mainly occurred during transitions or free-play periods and relieved teachers from this sense of responsibility. In contrast, we noted reports of negative emotions in response to challenging behaviours that were attributed to learning through positive reinforcement. We hypothesize 
that teachers may exhibit these responses because they feel partially responsible for the children's behaviours.

\section{Conclusion}

The present study revealed relationships between the cognitive, emotional, and behavioural components of teachers' attitudes toward challenging behaviours from pupils with ID. Our use of observational methods enabled the identification of the behaviours most frequently manifested by teachers and pupils. Our results did not highlight any significant correlations between what teachers reported they would do and their actual conduct, except for one behaviour. Such findings are a cautionary tale for the sole use of self-report questionnaires to be completed by teachers. Although the present study furthers our understanding of teachers' attitudes toward deviant and challenging behaviours, a few of its limitations must be noted. First, the fact that the study was conducted in a single school and among a restricted sample limits the generalization of our findings. Moreover, studies have shown that participants may respond to being observed (Gardner, 2000) and that naturalistic observation may be intrusive, eliciting unusual reactions in those being observed. However, we believe that these phenomena are tempered by the extended observation period, which may have promoted habituation (Harris \& Lahey, 1982) and enabled participants to be less reactive (Gardner, 2000; Ketele, 1987). Furthermore, younger participants do not manifest reactivity as acutely (Ketele, 1987). It is therefore plausible that pupils did not alter their behaviour in response to being observed.

The methods of this present study, although limiting in some respects, are nevertheless its greatest strengths. Indeed, observational methods offer substantial research benefits and are often used to describe social conduct (Mouchtouris, 2012). The outcomes of this study may help teachers critically examine their own conduct (Richardson \& Heckman, 1996). Knowing that there is a discrepency between predicted and actual conduct when faced with challenging behaviour can help teachers identify their attitudes toward their pupils. Also, the use of videos of their own behaviours or of others could help them become more aware of the type of intervention they actually implement. Furthermore, realizing that they spend a great amount of time responding to challenging behaviour could highlight the importance of implementing interventions that prevent 
challenging behaviour and the importance of understanding their causes. For a more comprehensive overview of the phenomenon of challenging behaviours, our findings could be replicated on a larger scale, among children belonging to different age groups and in inclusive classrooms. 


\section{References}

Antonak, R. F., \& Livneh, H. (1988). The measurement of attitudes toward people with disabilities. Methods, psychometrics, scales. Charles C. Thomas Publisher.

L'Abbé, Y., \& Morin, D. (2001). Comportements agressifs et retard mental : Compréhension et intervention. Editions Behaviora Inc.

Crocker, A. G., Mercier, C., Lachapelle, Y., Brunet, A., Morin, D., \& Roy, M. E. (2006). Prevalence and types of aggressive behaviour among adults with intellectual disabilities. Journal of Intellectual Disability Research, 50(9), 652-661.

Guikas, I., Morin, D., \& Bigras, M. (2016). Développement d'une grille d'observation : considérations théoriques et méthodologiques. Revue Francophone de la Déficience Intellectuelle, 27, 163-178.

Bailey, B. A., Hare, D. J., Hatton, C., \& Limb, K. (2006). The response to challenging behaviour by care staff: Emotional responses, attributions of cause and observations of practice. Journal of Intellectual Disability Research, 50(3), 199 211. https://doi.org/10.1111/j.1365-2788.2005.00769.x

Bromley, J., \& Emerson, E. (1995). Beliefs and emotional reactions of care staff working with people with challenging behaviour. Journal of Intellectual Disability Research, 39(4), 341-352. https://doi.org/10.1111/j.1365-2788.1995.tb00526.x

Chung, C. M., \& Harding, C. (2009). Investigating burnout and psychological wellbeing of staff working with people with intellectual disabilities and challenging behaviour: The role of personality. Journal of Applied Research in Intellectual Disabilities, 22(6), 549-560. https://doi.org/10.1111/j.1468-3148.2009.00507.x

Cohen, J. (1960). A coefficient of agreement for nominal scales. Educational and Psychological Measurement, 20(1), 37-46. https://doi. org/10.1177/001316446002000104

Cohen, J. (1988). Statistical power analysis for the behavioral sciences (2nd ed.). Lawrence Erlbaum Associates.

Cudré-Mauroux, A. (2010). Staff attributions about challenging behaviours of people with intellectual disabilities and transactional stress process: A qualitative 
study. Journal of Intellectual Disability Research, 54(1), 26-39. https://doi. org/10.1111/j.1365-2788.2009.01221.x

De Ruiter, K. P., Dekker, M. C., Verhulst, F. C., \& Koot, H. M. (2007). Developmental course of psychopathology in youths with and without intellectual disabilities. Journal of Child Psycholy and Psychiatry, 48(5), 498-507. https://doi. org/10.1111/j.1469-7610.2006.01712.x

Dilworth, J. A., Phillips, N., \& Rose, J. (2011). Factors relating to staff attributions of control over challenging behaviour. Journal of Applied Research in Intellectual Disabilities, 24(1), 29-38. https://doi.org/10.1111/j.1468-3148.2010.00570.x

Einfeld, S. L., \& Tonge, J. (1996). Population prevalence of psychopathology in children and adolescents with intellectual disability: II. Epidemiological findings. Journal of Intellectual Disability Research, 40(2), 99-109. https://doi. org/10.1046/j.1365-2788.1996.768768.x

Embregts, P. J. C. M., Didden, R., Huitink, C., \& Schreuder, N. (2009). Contextual variables affecting aggressive behaviour in individuals with mild to borderline intellectual disabilities who live in a residential facility. Journal of Intellectual Disability Research, 53(3), 255-264. https://doi. org/10.1111/j.1365-2788.2008.01132.x

Emerson, E., \& Bromley, J. (1995). The form and function of challenging behaviours. Journal of Intellectual Disability Research, 39(5), 388-398. https://doi. org/10.1111/j.1365-2788.1995.tb00543.x

Emerson, E., Kiernan, C., Alborz, A., Reeves, D., Mason, H., Swarbrick, R., Mason, L., \& Hatton, C. (2001). The prevalence of challenging behaviors: A total population study. Research in Developmental Disabilities, 22(1), 77-93. https://doi. org/10.1016/S0891-4222(00)00061-5

French, D. C., \& Conrad, J. (2001). School dropout as predicted by peer rejection and antisocial behavior. Journal of Research on Adolescence, 11(3), 225-244. https:// doi.org/10.1111/1532-7795.00011

Gardner, F. (2000). Methodological issues in the direct observation of parent-child interaction: Do observational findings reflect the natural behavior of participants? 
Clinical Child and Family Psychology Review, 3(3), 185-198. https://doi. org/10.1023/A:1009503409699

Grey, I. M., McClean, B., \& Barnes-Holmes, D. (2002). Staff attributions about the causes of challenging behaviours: Effects of longitudinal training in multi-element behaviour support. Journal of Learning Disabilities, 6(3), 297-312. https://doi. org/10.1177/1469004702006003037

Hall, S., Oliver, C., \& Murphy, G. (2001). Early development of self-injurious behavior: An empirical study. American Journal on Mental Retardation, 106(2), 189-199. https://doi.org/10.1352/0895-8017(2001)106<0189:EDOSIB >2.0.CO;2

Harris, C. F., \& Lahey, B. B. (1982). Subject reactivity in direct observational assessment: A review and critical analysis. Clinical Psychology Review, 2(4), 523-538. https:// doi.org/10.1016/0272-7358(82)90028-9

Hastings, R. P. (1995). Understanding factors that influence staff responses to challenging behaviour: An exploratory interview study. Mental Handicap Research, 8(4), 296-320. https://doi.org/10.1111/j.1468-3148.1995.tb00163.x

Hastings, R. P. (1997a). Staff beliefs about the challenging behaviors of children and adults with mental retardation. Clinical Psychological Review, 17(7), 775-790. https://doi.org/10.1016/S0272-7358(97)00050-0

Hastings, R. P. (1997b). Measuring staff perceptions of challenging behaviour: The Challenging Behaviour Attribution Scale (CHABA). Journal of Intellectual Disability Research, 41(6), 495-501. https://doi.org/10.1111/j.1365-2788.1997. $\underline{\text { tb00742.x }}$

Hastings, R. P. (2002). Do challenging behaviors affect staff psychological well-being? Issues of causality and mechanism. American Journal on Mental Retardation, 107(6), 455-467. https://doi.org/10.1352/0895-8017(2002)107<0455:DCBASP $>2$ $.0 . \mathrm{CO} ; 2$

Hastings, R. P. (2005). Staff in special education settings and behaviour problems: Towards a framework for research and practice. Educational Psychology, 25(23), 207-221. https://doi.org/10.1080/0144341042000301166 
Hastings, R. P., \& Brown, T. (2000). Functional assessment and challenging behaviors: Some future directions. Journal of the Association for Persons with Severe Handicaps, 25(4), 229-240. https://doi.org/10.2511/rpsd.25.4.229

Hastings, R. P., \& Brown, T. (2002). Behavioural knowledge, causal beliefs and selfefficacy as predictors of special educators' emotional reactions to challenging behaviours. Journal of Intellectual Disability Research, 46(2), 144-150. https:// doi.org/10.1046/j.1365-2788.2002.00378.x

Hastings, R. P., \& Remington, B. (1994). Staff behaviour and its implications for people with learning disabilities and challenging behaviours. British Journal of Clinical Psychology, 33(4), 423-438. https://doi.org/10.1111/j.2044-8260.1994.tb01140.x

Hastings, R. P., Remington, B., \& Hopper, G. M. (1995). Experienced and inexperienced health care workers' beliefs about challenging behaviours. Journal of Intellectual Disability Research, 39(6), 474-483. https://doi.org/10.1111/j.1365-2788.1995. $\underline{\mathrm{tb} 00567 . \mathrm{x}}$

Hensel, J. M., Lunsky, Y., \& Dewa, C. S. (2012). Exposure to client aggression and burnout among community staff who support adults with intellectual disabilities in Ontario, Canada. Journal of Intellectual Disability Research, 59(9), 910-915. https://doi.org/10.1111/j.1365-2788.2011.01493.x

Holden, B., \& Gitlesen, J. P. (2006). A total population study of challenging behaviour in the county of Hedmark, Norway: prevalence and risk markers. Research in Developmental Disabilities, 27(4), 456-465. https://doi.org/10.1016/j. ridd.2005.06.001

Hudson, A. M., Matthews, J. M., Gavidia-Payne, S. T., Cameron, C. A., Mildon, R. L., Radler, G. A., \& Nankervis, K. L. (2003). Evaluation of an intervention system for parents of children with intellectual disability and challenging behaviour. Journal of Intellectual Disability Research, 47(4), 238-249. https://doi. org/10.1046/j.1365-2788.2003.00486.x

Iacobucci, D., \& Wasserman, S. (1988). A general framework for the statistical analysis of sequential dyadic interaction data. Psychological Bulletin, 103(3), 379-390. https://doi.org/10.1037/0033-2909.103.3.379 
Jahoda, A., \& Wanless, L. K. (2005). Knowing you: The interpersonal perceptions of staff towards aggressive individuals with mild to moderate intellectual disabilities in situations of conflict. Journal of Intellectual Disability Research, 49(7), 544-551. https://doi.org/10.1111/j.1365-2788.2005.00693.x

Jenkins, R., Rose, J., \& Lovell, C. (1997). Psychological well-being of staff working with people who have have challenging behaviour. Journal of Intellectual Disability Research, 41(6), 502-511. https://doi.org/10.1111/j.1365-2788.1997.tb00743.x

Jones, C., \& Hastings, R. P. (2003). Staff reactions to self-injurious behaviours in learning disability services: Attributions, emotional responses and helping. British Journal of Clinical Psychology, 42(2), 189-203. https://doi. org/10.1348/014466503321903599

Kelly, Á., Carey, S., McCarthy, S., \& Coyle, C. (2007). Challenging behaviour: Principals' experience of stress and perception of the effects of challenging behaviour on staff in special schools in Ireland. European Journal of Special Needs Education, 22(2), 161-181. https://doi.org/10.1080/08856250701269507

Ketele, J.-M. (1987). Méthodologie de l'observation. De Boeck-Wesmael.

Kozak, A., Kersten, M., Schillmöller, Z., \& Nienhaus, A. (2013). Psychosocial workrelated predictors and consequences of personal burnout among staff working with people with intellectual disabilities. Research in Developmental Disabilities, 34(1), 102-115. https://doi.org/10.1016/j.ridd.2012.07.021

Lambrechts, G., Kuppens, S., \& Maes, B. (2009). Staff variables associated with the challenging behaviour of clients with severe or profound intellectual disabilities. Journal of Intellectual Disability Research, 53(7), 620-632. https://doi. org/10.1111/j.1365-2788.2009.01162.x

Lambrechts, G., Van Den Noortgate, W., Eeman, L., \& Maes, B. (2010). Staff reaction to challenging behaviour: An observation study. Research in Developmental Disabilities, 31(2), 525-535. https://doi.org/10.1016/j.ridd.2009.12.004

Male, D., \& May, D. (1997a). Burnout and workload in teachers of children with severe learning difficulties. British Journal of Learning Disabilities, 25(3), 117-121. https://doi.org/10.1111/j.1468-3156.1997.tb00023.x 
Male, D., \& May, D. (1997b). Stress, burnout and workload in teachers of children with special educational needs. British Journal of Special Education, 24(3), 133-140. https://doi.org/10.1111/1467-8527.t01-1-00029

Mills, S., \& Rose, J. (2011). The relationship between challenging behaviour, burnout and cognitive variables in staff working with people who have intellectual disabilities. Journal of Intellectual Disability Research, 55(9), 844-857. https:// doi.org/10.1111/j.1365-2788.2011.01438.x

Ministère de l'Éducation du Loisir et du Sport. (2006). Programme de formation de l'école québécoise. Éducation préscolaire, enseignement primaire. Bibliothèque nationale du Québec. http://www1.mels.gouv.qc.ca/sections/ programmeFormation/pdf/prform2001nb.pdf

Mitchell, G., \& Hastings, R. P. (1998). Learning disability care staff's emotional reactions to aggressive challenging behaviours: Development of a measurement tool. British Journal of Clinical Psychology, 37(4), 441-449. https://doi. org/10.1111/j.2044-8260.1998.tb01401.x

Mitchell, G., \& Hastings, R. P. (2001). Coping, burnout, and emotion in staff working in community services for people with challenging behaviors. American Journal on Mental Retardation, 106(5), 448-459. https://doi. org/10.1352/0895-8017(2001)106<0448:CBAEIS $>2.0 . C O ; 2$

Mossman, D. A., Hastings, R. P., \& Brown, T. (2002). Mediators' emotional responses to self-injurious behavior: An experimental study. American Journal on Mental Retardation, 107(4), 252-260. https://doi. org/10.1352/0895-8017(2002)107<0252:MERTSI $>2.0 . C O ; 2$

Mouchtouris, A. (2012). L'observation: Un outil de connaissance du monde. L'Harmattan.

Noldus Information Technology. (2012). The Observer XT: The next generation of observation software (version 11) [Computer software]. Noldus Information Technology.

Nunnally, J. C. (1967). Psychometric theory. McGraw-Hill.

Rae, H., \& Murray, G. (2011). Teaching staff knowledge, attributions and confidence in relation to working with children with an intellectual disability and challenging 
behaviour. British Journal of Learning Disabilities, 39(4), 295-301. https://doi. org/10.1111/j.1468-3156.2010.00667.x

Richardson, V., \& Heckman, P. (1996). Rétroaction vidéo et amitié critique. Des prémisses de l'action pédagogique au changement scolaire. Revue des sciences de l'éducation, 22(3), 635-650. https://doi.org/10.7202/031897ar

Rosenberg, M. J., \& Hovland, C. I. (1960). Cognitive, affective, and behavioral components of attitude. In M. Rosenberg, C. Hovland, W. McGuire, R. Abelson, \& J. Brehm (Eds.), Attitude organisation and change (pp. 1-14). Yale University Press.

Tassé, M. J., \& Craig, E. M. (1999). Critical issues in cross-cultural assessment of adaptative behavior. In R. L. Schalock \& D. L. Braddock (Eds.), Adaptative behavior and its measurement: Implications for the field of mental retardation (pp. 161-83). American Association of Mental Retardation.

Tassé, M. J., Sabourin, G., Garcin, N., \& Lecavalier, L. (2010). Définition d'un trouble grave du comportement chez les personnes ayant une déficience intellectuelle. Canadian Journal of Behavioural Science, 42(1), 62-69. https://doi.org/10.1037/ $\underline{\mathrm{a} 0016249}$

Van Oorsouw, W. M. W. J., Embregts, P. J. C. M., \& Sohier, J. (2011). Verbal and nonverbal emotional behaviour of staff: A first attempt in the development of an observation instrument. Research in Developmental Disabilities, 32(6), 24082414. https://doi.org/10.1016/j.ridd.2011.07.019

Wallander, J. L., Koot, H. M., \& Dekker, M. C. (2003). Psychopathology in children and adolescents with intellectual disability: Measurement, prevalence, course, and risk. International Review of Research in Mental Retardation, 26, 93-134. https:// doi.org/10.1016/S0074-7750(03)01003-6

Wanless, L. K., \& Jahoda, A. (2002). Responses of staff towards people with mild to moderate intellectual disability who behave aggressively: A cognitive emotional analysis. Journal of Intellectual Disabilitiy Research, 46(6), 507-516. https://doi. org/10.1046/j.1365-2788.2002.00434.x 
Willaye, E., \& Magerotte, G. (2008). Évaluation et intervention auprès des comportements-défis : déficience intellectuelle et-ou autisme. De Boeck Université.

Zanna, M. P., \& Rempel, J. K. (1988). Attitudes: A new look at the old concept. In D. Bar-Tal \& A.W. Kruglanski (Eds.), The social psychology of knowledge (pp. 315-34). Cambridge University Press.

Zijlmans, L. J. M., Embregts, P. J. C. M., Bosman, A. M. T., \& Willems, A. P. A. M. (2012). The relationship among attributions, emotions, and interpersonal styles of staff working with clients with intellectual disabilities and challenging behavior. Research in Developmental Disabilities, 33(5), 1484-1494. https://doi. org/10.1016/j.ridd.2012.03.022 